\title{
Life cycle assessment: an application to poplar for energy cultivated in Italy
}

\author{
Jacopo Bacenetti, ${ }^{1}$ Sara González-García,, ${ }^{2}$ Aira Mena, ${ }^{1}$ Marco Fiala1 \\ ${ }^{1}$ Department of Agricultural Engineering, University of Milano, Italy; ${ }^{2}$ Department of Chemical \\ Engineering, School of Engineering, University of Santiago de Compostela, Spain
}

\begin{abstract}
The development of the bioenergy sector has led to an increasing interest in energy crops. Short rotation coppices (SRC) are forestry management systems in which fast-growing tree species are produced under intensive cultivation practices to obtain high wood chips yields. In Italy, most SRC plantations consist of poplar biomass-clones. SRC plantations can be carried out with different management systems with diverse cutting times; consequently, the cultivation system can be crucial for attaining high yields depending on: i) short and ii) medium cutting frequency. Nowadays, the larger part of Italian SRC is based on 2-year cutting short rotation forestry (SRF) but the best quality of wood chips is linked to 5-year plantation medium rotation forestry (MRF). This work compares an SRF and an MRF poplar plantation located in the Po Valley in northern Italy. In particular, a life cycle assessment (LCA) was carried out to evaluate their energy demand and greenhouse gas emissions. The LCA software SimaPro 7.10 was used to create the LCA model and to assure an accurate impact assessment calculation. The analysis shows several differences between MRF and SRF in terms of fertiliser requirements and intensive agricultural activities. Results highlight that MRF produces a more sustainable wood chip production than SRF according to energy and environmental con-
\end{abstract}

Correspondence: Jacopo Bacenetti, Department of Agricultural Engineering, University of Milano, Italy. Tel. +39.0250316869 - Fax: +39.0250316845 .

E-mail: jacopo.bacenetti@unimi.it

Key words: energy crops, life cycle assessment, poplar, medium rotation forestry, short rotation forestry.

Acknowledgements: the present work is funded by Regione Lombardia Fondo per la Promozione di Accordi Istituzionali, project BIOGESTECA 15083/RCC". The authors thank Regione Lombardia, which financed a Postdoctoral Research Fellowship (Progetto Dote Ricerca financed by FSE Regione Lombardia).

Dr. S. González-García expresses her gratitude to the Spanish Ministry of Education for financial support (Grant reference: EX20090740) for a Postdoctoral Research Fellowship.

Received for publication: 4 May 2012.

Accepted for publication: 5 September 2012.

(O) Copyright J. Bacenetti et al., 2012

Licensee PAGEPress, Italy

Journal of Agricultural Engineering 2012; XLIII:e11

doi:10.4081/jae.2012.e11

This article is distributed under the terms of the Creative Commons Attribution Noncommercial License (by-nc 3.0) which permits any noncommercial use, distribution, and reproduction in any medium, provided the original author(s) and source are credited. cerns. Furthermore, hot spots were identified in both SRF and MRF due to the high energy consumption and the related emissions. These hot spots were: i) mineral fertilisation; ii) mechanical weed-control; iii) harvesting and biomass transport.

\section{Introduction}

European farmers are becoming increasingly interested in the production of energy crops following the most recent changes in the common agricultural policy and the rapid development of the bioenergy sector (Spinelli et al., 2008). Among cropping systems, the short rotation coppices (SRC) seem to reflect the farmers' economical expectations. In fact, SRC allows (Spinelli et al., 2008) shorter return times than traditional wood plantations (at least 30 years). The SRC are wood crops usually defined as silvicultural management practices in which fast-growing tree species are cultivated under intensive management (weed and pest control, use of fertilisers and irrigation) in order to obtain high biomass yields (Bergante et al., 2010). However, in Italy, the study of SRCs is still new (Manzone et al., 2009), although over the last 15 years, encouraged by very favourable grant programmes, SRC have been established on about 6500 ha in the Po Valley area (Gasol et al., 2010; Bergante et al., 2010), mainly (>60\%) in the Lombardy Region (Fiala et al., 2010). Furthermore, in this area, there is a growing interest in the production of biofuels since several thermoelectric power plants fed by biomass have been recently built (Bergante et al., 2010).

In Italy, species that can be used are poplar, willow, black locust and eucalyptus, but most plantations consist of poplar biomassclones (Fiala et al., 2010; Bergante et al., 2010). This species has proved to be extremely well suited to biomass production due to its fast initial growth, high photosynthetic capacity, and large wood biomass production.

In Italy, poplar energy crop cultivation is carried out under intensive conditions and the rotation (or cutting frequency) is usually shorter (2 years) than in other European countries (3-4 years in Sweden and the UK). The cutting frequency of poplar coppice plantations depends on the plant density and on the growth rate. The development of new poplar clones, as well as the improvement in cultivation techniques, has led to a considerable increase in biomass yield $\left(>17 \mathrm{t}_{\mathrm{DM}} \cdot \mathrm{ha}^{-1} \cdot \mathrm{yr}^{-1}\right.$; dry matter) (Bergante et al., 2010).

SRC poplar plantations consist of coppice periodically cut clear to stimulate sucker growth. Different management systems can be used and these are based on either short or medium cutting frequency. These systems are respectively called short rotation forestry (SRF) and medium rotation forestry (MRF), and the main differences between them concern: i) type of propagation materials (SRF: cuttings; MRF: stumps); ii) plant density (SRF: $5500-6500$ cuttings $^{-h^{-1}}{ }^{-1}$; MRF: $1100-1300$ stumps $\cdot$ ha $^{-1}$ ); iii) cutting interval (SRF: 1-2 years; MRF: $>5$ years).

Nowadays, most Italian short rotation crops are based on 2-year cut- 
ting but the best quality of biofuel originates from 5-year plantations, mainly because of the lower ash content that results from the higher wood/bark ratio (Guidi et al., 2008). Consequently, in the near future, MRF will be more widespread.

This work aims to assess both the energy demand and the greenhouse gas (GHG) emissions related to the poplar cultivation in the Po Valley in northern Italy, considering two different cultivation systems (SRF and MRF) applied to real plantations.

The general aims of this study are to: i) gather the inventory data both for SRF and MRF, quantifying their effects on the environment and energy resources; ii) identify the cultivation systems hot spots; iii) suggest some possible improvements. To study the impact of Italian poplar plantations, a life cycle assessment (LCA) has been carried out. Two productive scenarios have been analysed based on experimental data collected from commercial SRF and MRF plantations. The purpose of the LCA has been to determine the best current production practice from an environmental point of view.

\section{Materials and methods}

The life cycle assessment (LCA) approach is a methodology for the comprehensive valuation of the impact that a product brings on the environment throughout its whole life cycle. LCA is an objective process to evaluate the environmental burdens associated with a product by measuring the consumption of natural resources and the emissions to environmental compartments, and to identify and implement opportunities to achieve environmental improvements.

The LCA software SimaPro 7.10, developed by PRé Consultants (PRé Consultants bv, Amersfoort, The Netherlands, http://www.pre-sustainability.com/), has been used to create the LCA model and to assure the impact assessment calculation.

Following ISO 14040 standard guidelines (ISO, 2006), all the production factors have been considered. LCA defines the environmental profile for the assessed production by quantifying the environmental effects.

In this paper, for both poplar SRF and MRF cultivation systems, the global warming potential (GWP) and the cumulative energy demand (CED) have been calculated.

The GWP is a relative measure of how much heat a GHG traps in the atmosphere; it compares the amount of heat contained in a certain mass of the gas in question to the amount of heat trapped by a similar mass of carbon dioxide. The CED represents the whole energy demand, (valued as primary energy) related to the production, use and disposal of an economic good.

The cumulative energy output (CEO) has been calculated considering the total wood chip harvested dry mass and its lower heating value (LHV) (Fiala et al., 2010). The net energy ratio (NER) is the ratio between the CEO and the CED.

Since the system boundary set in this study does not take into consideration the conversion of the wood chips into energy (heat and/or electricity), according to other short rotation crops, LCA studies focused on wood chip production (Heller et al., 2004; González-García et al., 2012); the cultivated surface (i.e., one hectare of poplar plantation under the two analysed cultivation systems) has been selected as functional unit (FU).

\section{Poplar cultivations}

Both the SRF and MRF analysed plantations are located on two different farms of the Lombardy Region, at Ostiano, in the province of Cremona $\left(45^{\circ} 12^{\prime} \mathrm{N}, 10^{\circ} 15^{\prime} \mathrm{E}\right)$. This area has a sub-continental climate with rainfall mainly concentrated in spring and autumn (yearly average: $745 \mathrm{~mm}_{\text {year }}{ }^{-1}$ ) and daily temperatures of $9.3^{\circ} \mathrm{C}$ (average mini- mum) and $20.1^{\circ} \mathrm{C}$ (average maximum). Both the energy crop cultivations can be divided into the following phases: i) soil preparation and planting; ii) management and harvesting; iii) soil restoration.

The general schemes of SRF (2-year cutting frequency) and MRF (5year cutting frequency) cultivation systems are shown in Figure 1.

Table 1 presents all the field operations carried out during the whole SRF and MRF cultivation period as well as the years in which they are carried out. The main characteristics of the two poplar plantations are reported in Table 2 .

\section{Soil preparation and planting}

During the $1^{\text {st }}$ year, according to both cultivation systems, soil was: i) fertilised with cattle manure (rate $50 \mathrm{tha}^{-1}$ ); ii) ploughed; and iii) harrowed. The manure applied presents a moisture content of $80-82 \%$ wet basis (wb), an average content of $4.5 \mathrm{~kg}$ of $\mathrm{N} \mathrm{t}^{-1}, 2.0 \mathrm{~kg}$ of $\mathrm{P}_{2} \mathrm{O}_{5} \mathrm{t}^{-1}$ and $3.5 \mathrm{~kg}$ of $\mathrm{K}_{2} \mathrm{O} \mathrm{t}^{-1}$.

After soil preparation, different planting programmes were adopted for the SRF and the MRF systems. Unrooted $22 \mathrm{~cm}$ cuttings of $A F 2$ poplar clone were planted in the SRF plantation with a density of 5560 cuttings ha ${ }^{-1}$ (distance of $0.5 \mathrm{~m}$ on each row, $2.8-3.0 \mathrm{~m}$ between rows). For MRF, 2 m plant-rods of $A F 2$ poplar clone were planted with a density of 1150 plants rod ha ${ }^{-1}$ (distance of 2.8-3.0 m on each row, 2.8-3.0 m between rows). In both plantations, lanes allow the use of conventional wheeled tractors to perform all the mechanical operations.

After planting, the chemical weed-control was carried out; spraying glyphosate (concentration $31 \% ; 4 \mathrm{~kg} \mathrm{ha}^{-1}$ ) was sprayed once for the SRF and twice for the MRF. The two sprayings of the MRF was neces-
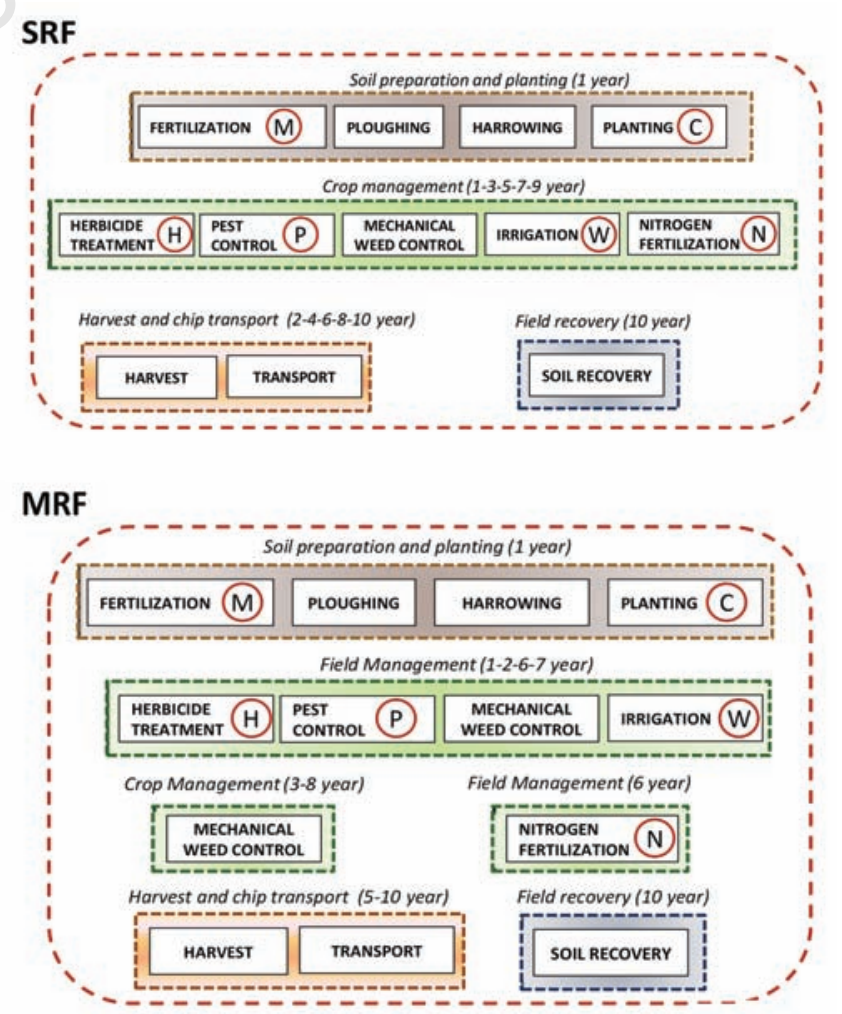

Figure 1. Scheme of the system boundaries for short rotation forestry (SRF) and medium rotation forestry (MRF) poplar cultivations. $M$, manure; $C$, cuttings; $H$, herbicide; $P$, pesticide; $N$, nitrogen fertilization; $W$, water. 
Table 1. Poplar short rotation forestry and medium rotation forestry: field operations timeline and inventory data.

\begin{tabular}{|c|c|c|c|c|c|c|c|}
\hline Operation & $\begin{array}{l}\text { Year } \\
\text { of passing }\end{array}$ & $\begin{array}{l}\text { Tractor (A) } \\
\text { Mass } \\
\text { and } \\
\text { power }\end{array}$ & $\begin{array}{l}\text { Imple } \\
\text { Type of } \\
\text { machine }\end{array}$ & $\begin{array}{l}\text { ement } \\
\text { Mass } \\
(\mathrm{kg})\end{array}$ & $\begin{array}{l}\text { Operating } \\
\text { time* } \\
\left(h_{h} \mathbf{h a}^{-1}\right)\end{array}$ & $\begin{array}{c}\text { A+B } \\
\text { Fuel } \\
\text { consumption* } \\
\left(\mathrm{kg} \mathrm{ha}^{-1}\right)\end{array}$ & Rate* \\
\hline \multicolumn{8}{|c|}{ Soil preparation and planting (1 $1^{\text {st }}$ year) } \\
\hline Organic fertilization & SRF and MRF: 1 & $\begin{array}{l}6730 \mathrm{~kg} \\
120 \mathrm{~kW}\end{array}$ & Manure spreader & 2500 & 0.45 & 4.0 & $\begin{array}{c}\text { SRF and MRF } \\
50 \text { t.ha }^{-1} \text { manure }^{\circ}\end{array}$ \\
\hline Ploughing & SRF and MRF: 1 & $\begin{array}{l}6730 \mathrm{~kg} \\
120 \mathrm{~kW}\end{array}$ & Plough & 1500 & 1.70 & 20.5 & - \\
\hline Harrowing & SRF and MRF: 1 & $\begin{array}{l}5050 \mathrm{~kg} \\
90 \mathrm{~kW}\end{array}$ & Rotary harrow & 1000 & 2.00 & 23.5 & - \\
\hline Planting & SRF and MRF: 1 & $\begin{array}{l}6730 \mathrm{~kg} \\
120 \mathrm{~kW}\end{array}$ & Planter & 630 & 1.42 & $\begin{array}{r}5 \\
11 \\
\end{array}$ & $\begin{array}{c}\text { SRF: } \\
5560 \text { cuttings hat } \\
\text { MRF: } \\
150 \text { plant rods } \cdot h^{-1}\end{array}$ \\
\hline Chemical weed control $^{\#}$ & SRF: 1 & $\begin{array}{l}4580 \mathrm{~kg} \\
80 \mathrm{~kW}\end{array}$ & Sprayer & 550 & 0.33 & 3.3 & $\begin{array}{c}\text { SRF and MRF } \\
4 \mathrm{~kg} \cdot \mathrm{ha}^{-1} \\
\text { MRF: } \mathrm{1}^{-1}\end{array}$ \\
\hline Irrigation $\S$ & SRF and MRF: 1 & - & - & - & - & - & $\begin{array}{l}\text { SRF and MRF } \\
400 \mathrm{~m}^{3} \cdot \mathrm{ha}^{-1}\end{array}$ \\
\hline Pest control^ ${ }^{\wedge}$ & SRF and MRF: 1 & $\begin{array}{l}4580 \mathrm{~kg} \\
80 \mathrm{~kW}\end{array}$ & Sprayer & 550 & 0.33 & 3.3 & $\begin{array}{c}\text { SRF and MRF } \\
2 \mathrm{~kg}^{-\mathrm{ha}^{-1}}\end{array}$ \\
\hline Chemical weed control* & $\begin{array}{l}\text { SRF: } 1 \\
\text { MRF: } 1-1\end{array}$ & $\begin{array}{l}4580 \mathrm{~kg} \\
80 \mathrm{~kW}\end{array}$ & Sprayer & 550 & 0.33 & 3.3 & $\begin{array}{c}\text { SRF and MRF } \\
4 \mathrm{~kg} \cdot \mathrm{ha}^{-1}\end{array}$ \\
\hline Mechanical weed control & SRF and MRF: 1 & $\begin{array}{l}5050 \mathrm{~kg} \\
90 \mathrm{~kW}\end{array}$ & Rotary harrow & 1000 & 2.20 & 25.3 & - \\
\hline \multicolumn{8}{|c|}{ Wood chips harvesting/transport and crop managing } \\
\hline Harvesting & $\begin{array}{l}\text { SRF: 2-4-6-8-10 } \\
\text { MRF: } 5-10\end{array}$ & $\begin{array}{c}13560 \mathrm{~kg} \\
343 \mathrm{~kW} \\
17500 \mathrm{~kg} \\
200 \mathrm{~kW} \\
5050 \mathrm{~kg} \\
90 \mathrm{~kW} \\
16000 \mathrm{~kg} \\
150 \mathrm{~kW}\end{array}$ & $\begin{array}{c}\text { Combine harvester } \\
\text { Harvester } \\
\text { Forestry } \\
\text { trailer } \\
\text { Chipper }\end{array}$ & $r-$ & $\begin{array}{l}1.20 \\
3.08 \\
5.00\end{array}$ & $\begin{array}{l}72.0 \\
126.6 \\
61.9 \\
100.7\end{array}$ & - \\
\hline Biomass transport & $\begin{array}{l}\text { SRF: } 2-4-6-8-10 \\
\text { MRF: } 5-10\end{array}$ & $\begin{array}{l}4580 \mathrm{~kg} \\
80 \mathrm{~kW}\end{array}$ & 3 tipping trailers & 5500 & 2.50 & $\begin{array}{l}16.0 \\
17.5\end{array}$ & \\
\hline Nitrogen fertilization $\$$ & $\begin{array}{l}\text { SRF: } 3-5-7-9 \\
\text { MRF: } 6\end{array}$ & $\begin{array}{l}5050 \mathrm{~kg} \\
90 \mathrm{~kW}\end{array}$ & Fertilizer spreader & 350 & 0.28 & 3.4 & $\begin{array}{l}\text { SRF:80 kg N.ha-1 } \\
\text { MRF:200 kg N.ha }\end{array}$ \\
\hline Chemical weed control** & $\begin{array}{l}\text { SRF: } 3-5-7-9 \\
\text { MRF: } 2-6-6-7\end{array}$ & $\begin{array}{l}4580 \mathrm{~kg} \\
80 \mathrm{~kW}\end{array}$ & Sprayer & 550 & 0.33 & 3.3 & $\begin{array}{l}\text { SRF:4 kg.ha-1 } \\
\text { MRF:2 kg.ha }{ }^{-1}\end{array}$ \\
\hline Pest control^ ${ }^{\wedge}$ & $\begin{array}{l}\text { SRF: } 3-5-7-9 \\
\text { MRF: 2-6-7 }\end{array}$ & $\begin{array}{l}4580 \mathrm{~kg} \\
80 \mathrm{~kW}\end{array}$ & Sprayer & 550 & 0.33 & 3.3 & $\begin{array}{c}\text { SRF and MRF } \\
2{\mathrm{~kg} \cdot h \mathrm{~h}^{-1}}^{-1}\end{array}$ \\
\hline Mechanical weed control & SRF: $3-5-7-9$ & $\begin{array}{c}5050 \mathrm{~kg} \\
90 \mathrm{~kW}\end{array}$ & Rotary harrow & 1000 & 2.20 & 25.3 & MRF: 2-2-3-6-6-7-7-8 \\
\hline Irrigation & $\begin{array}{l}\text { SRF: 3-5-7-9 } \\
\text { MRF: 2-5-6 }\end{array}$ & - & - & - & - & - & $\begin{array}{c}\text { SRF and MRF: } \\
400 \mathrm{~m}^{3} \cdot \mathrm{ha}^{-1}\end{array}$ \\
\hline \multicolumn{8}{|l|}{ Soil restoring } \\
\hline Soil restoration & SRF and MRF: 10 & $\begin{array}{l}6730 \mathrm{~kg} \\
120 \mathrm{~kW}\end{array}$ & Hoeing machine & 1000 & 5.00 & 60.0 & - \\
\hline
\end{tabular}

SRF, short rotation forestry; MRF, medium rotation forestry. *Values related to a single passing; ${ }^{\circ}$ Manure composition: 80-82\% moisture content, $4.5 \mathrm{~kg} \mathrm{~N} \cdot \mathrm{t}^{-1}, 2.0 \mathrm{~kg} \mathrm{P}_{2} \mathrm{O}_{5} \cdot \mathrm{t}^{-1}, 3.5 \mathrm{~kg} \mathrm{~K}_{2} \mathrm{O} \cdot \mathrm{t}^{-1}$; ${ }^{\sharp} \mathrm{Glyphosate}(31 \%)$; ${ }^{\S}$ Water from the near river without pumping system; ${ }^{\wedge}$ Deltamethrin; ${ }^{\circledR}$ Urea (46\%); **Gluphosinate-ammonium (11.3\%). 
sary to control a climbing weed (Convolvulus spp.). Pest control requires only one treatment according to both the cultivation systems, using gluphosinate-ammonium (concentration 11.3\%; $2 \mathrm{~kg} \mathrm{ha}^{-1}$ ).

A mechanical weed-control operation (soil light-harrowing) was also carried out and, finally, due to the high water needs of poplar, plantations were irrigated using $400 \mathrm{~m}^{3} \cdot \mathrm{ha}^{-1}$ of water collected from the near Oglio river and distributed through canals by gravity; it is not, therefore, necessary to pump water.

\section{Wood chip harvesting/transport and crop management}

\section{Short rotation forestry}

According to this system, harvesting took place in years $2,4,6,8$ and 10 using a self-propelled forage combine harvester equipped with a special biomass-header (Fiala and Bacenetti, 2012a and 2012b). The harvester directly loads the fresh chipped biomass on the trailers (no. 3 tipping trailers pulled by wheel tractors), which transport the material to the farm storage (distance: $2.5 \mathrm{~km}$ ). A cumulative wood chip production of $168.5 \mathrm{t}_{\mathrm{DM}} \cdot \mathrm{ha}^{-1}$ has been measured in this plantation (Fiala and Bacenetti, 2012a and 2012b).

After each harvesting operation, excluding the last one, the following operations have been carried out: i) nitrogen fertilisation (urea $46 \% \mathrm{~N}$, $80 \mathrm{~kg} \mathrm{~N} \cdot \mathrm{ha}^{-1}$ ); ii) weed control (gluphosinate-ammonium: concentra-

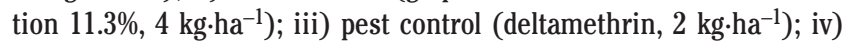
mechanical weed control; and v) irrigation $\left(400 \mathrm{~m}^{3} \cdot \mathrm{ha}^{-1}\right)$.

\section{Medium rotation forestry}

In this system, although the total duration is ten years, cutting take place only twice (every 5 years), using: i) a self-propelled harvester (felling operation); ii) a tractor coupled with a trailer equipped with pincers (whole tree transport from field to chipping place); and iii) a fixed wood chipper. The chipping machine directly loads the fresh biomass on trailers (no. 3 tipping trailers pulled by wheel tractors) which transport the material to the farm storage (distance: $2.0 \mathrm{~km}$ ). The cumulative wood chip production of the MRF plantation has been estimated to be $173 \mathrm{t}_{\mathrm{DM}} \cdot \mathrm{ha}^{-1}$ ( $35 \mathrm{t}_{\mathrm{WB}} \mathrm{ha}^{-1}$; moisture $55 \% \mathrm{wb}$ ).

Crop management includes: i) nitrogen fertilization (urea $46 \% \mathrm{~N}$, $200 \mathrm{~kg} \cdot \mathrm{ha}^{-1}$ of N) after the harvesting operation excluding the last one; ii) weed control (gluphosinate-ammonium: concentration 11.3\%, 4 $\mathrm{kg} \cdot \mathrm{ha}^{-1}$ ) in years 2, 6 (two times) and 7; iii) pest control (deltamethrin, $2 \mathrm{~kg} \cdot \mathrm{ha}^{-1}$,) in years 2,6 and 7 ; iv) mechanical weed-control in years 2 (two times), 3, 6 (two times), 7 (two times) and 8; v) irrigation (400 $\left.\mathrm{m}^{3} \cdot \mathrm{ha}^{-1}\right)$ in years 2,5 and 6 .

\section{Soil restoring}

In both the cultivation systems, after the last biomass harvesting ( $10^{\text {th }}$ year), the soil will be restored by a hoeing machine.

\section{Inventory analysis}

A central step of LCA consists in making a model of the product life cycle with all the environmental input and output; this data collection stage is usually named Life Cycle Inventory (LCI).

Primary and site-specific information has been collected mainly by local tests as well as interviewing the two farmers involved. The two SRC plantations have not yet been removed; SRF is in its $5^{\text {th }}$ year while MRF is in its $4^{\text {th }}$.

In detail, for both the poplar cultivation systems, the data on technical characteristics of machines, the operating time and the fuel consumption originate from field trials, specifically carried out on organic and mineral fertilization, ploughing, chemical and mechanical weed control, and pest control. For the SRF system, experimental data from years 2 and 4 were collected on biomass harvesting and transport operations while for the MRF system, since the plantation has not been yet harvested, the technical data refer to previous studies carried out in similar conditions (Fiala et al., 2010; Bergante, 2010; González-García et al., 2012; Bacenetti and Fiala, 2011).

Equally, since for both the SRF and MRF systems the final soil restoration has not been carried out (poplar cycle still in progress), the data utilised in the analysis are gathered from other research (Gasol et al., 2009; Bacenetti and Fiala, 2011; Fiala and Bacenetti, 2012a and 2012b).

Secondary data for the input factors (urea, deltamethrin, glyphosate and gluphosinate-ammonium, oil and lubricants) have been assumed from the Ecoinvent 2.2 Database (Althaus et al., 2007). The production cost of the cattle manure has not been included in the analysis (byproduct resulting from another process); only its distribution and the derived diffuse emissions have been analysed.

Carbon stored inside the biomass has been estimated on the basis of the carbon percentage of dried biomass (Fiala et al., 2010); both above and below ground biomass (roots and stools) have been considered since the latter represents a potential pool for carbon storage. A below/above ground biomass ratio of 0.20 (Matthews, 2001) has been assumed. For both the SRF and MRF cultivation systems, no change in the overall soil carbon content has been assumed because the fields were previously dedicated to poplar for industrial purposes (paper and furniture). A wood chip LHV of $18.5 \mathrm{GJ} \cdot \mathrm{t}_{\mathrm{DM}}{ }^{-1}$ has been considered (Fiala et al., 2010).

\section{Methodology}

Among the steps defined within the life cycle impact assessment stage of the standardized LCA methodology, only classification and characterisation stages (IS0, 2006) (Guinée, 2011) were considered here.

Normalisation and weighting were not conducted because these optional aspects did not provide additional significant information pertinent to the study objectives.

The assessment has been focused on the GWP. The characterisation model developed by the Intergovernmental Panel on Climate Change (IPCC) was selected for development of the characterisation factors, expressed as the global warming potential for a time horizon of 100 years (GWP100).

Furthermore, an energy analysis was carried out based on the cumulative non-renewable fossil and nuclear CED (VDI - Richtlinie, 1997), computed according to Althaus et al. (2009).

SimaPro 7.3.2 software was used for the computational implementation of the inventories (PRé Consultants bv).

\section{Allocation procedure}

Since only the production of useful biomass (wood chips) has been considered, the allocation is not required and all the environmental effects have been assigned to the harvested wood chips. During poplar

Table 2. General information about the short rotation forestry and medium rotation forestry poplar plantations.

\begin{tabular}{|c|c|c|c|}
\hline \multicolumn{2}{|c|}{ Unit of measure } & SRF & MRF \\
\hline Age & Year & 5 & 4 \\
\hline Field size & ha & 2.398 & 2.187 \\
\hline Field shape & - & Polygonal & Polygonal \\
\hline Average distance from farm storage & $\mathrm{km}$ & 2.5 & 2.0 \\
\hline Average basal tree diameter at cut & $\mathrm{cm}$ & 9.90 & $21^{*}$ \\
\hline Duration & Year & 10 & 10 \\
\hline Wood chips yield & 1.ha ${ }^{-1} \cdot$ year $^{-1}$ & 16.85 & $17.30^{\circ}$ \\
\hline
\end{tabular}


growth, further biomass is produced but not harvested (leaves and stools); just like parts of the natural process in the coppice management system, it was assumed that these bio-materials do not cause emissions.

\section{Results}

Table 3 reports the energetic (CEO, CED, NER) and the environmental (fixed $\mathrm{CO}_{2}$, $\mathrm{GHG}, \mathrm{GWP}$ ) performances, related to the selected FU for both the SRF and the MRF cultivation systems. Similarly, Figure 2 shows the comparison between the MRF and the SRF performances, assuming the SRF system as baseline.

From the environmental point of view, the production of wood chips from the MRC system results in lower GHG emissions (-6.2\%) than the SRF system; also considering the CED, the best responses are achieved from the MRF (-11.0\%). These results agree with other recent studies on poplar SRF (Bergante et al., 2010) and on black locust SRF (González-García et al., 2012).

\section{Global warming potential}

The production of renewable biomass (above and below ground) presents a carbon sink due to $\mathrm{CO}_{2}$ taken up by the biomass during its growth. This biomass $\mathrm{CO}_{2}$ absorption offsets the $\mathrm{GHG}$ emissions related to the SRC cultivation, like the $\mathrm{CO}_{2}$ caused from: i) fuel combustion in tractor (or self-propelled machine) engines; ii) the fabrication of agro-chemicals; and iii) the on-field emissions $\left(\mathrm{N}_{2} \mathrm{O}\right.$ from fertilisers, which contribute to the net GWP score and are included in the analysis). Table 4 shows the contribution of each operation involved in both poplar management systems in GWP: 5660 and $5307 \mathrm{t}$ of fossil $\mathrm{CO}_{2} / \mathrm{ha}^{-1}$ originate from all activities associated, respectively, to the SRF and the MRF cultivation systems. But, at the same time, -370.8 and $-380.6 \mathrm{t} \mathrm{CO}_{2}$ are fixed during the biomass growth for the SRF and the MRF systems, respectively.

In terms of GHG emissions, the hot spots (Table 4) are: i) the mechanical weed control; ii) the fabrication of urea; iii) the harvesting and biomass transport. $\mathrm{N}_{2} \mathrm{O}$ and fossil- $\mathrm{CO}_{2}$ dominate the $\mathrm{GHG}$ emissions with shares of $18.1 \%$ and $81.8 \%$ in the SRF and $22.7 \%$ and $75.6 \%$ in the MRF system, respectively.

\section{Energy performances}

The consumption of different non-renewable (fossil and nuclear) and renewable sources has been analyzed in terms of energy equivalent. Concerning the CED, 59.7 $\mathrm{GJ} \mathrm{ha}^{-1}$ and $84.6 \mathrm{GJ} \mathrm{ha}^{-1}$ are required throughout the 10-year plantation under MRF and SRF cultivations, respectively; this means that the SRF cultivation system requires approximately $12 \%$ more energy than the MRF system. This is mainly due to the higher rate of fertilisers and the more rigorous cycle management (in terms of harvesting, fertilizing and pest control events). $\mathrm{N}$ fertilization, mechanical weed-control and wood chip harvesting represent the energy input hot spots, with corresponding contributions of $28 \%, 26 \%$ and $12 \%$ in the SRF system, and $24 \%, 15 \%$ and $31 \%$ in the MRF system.

Also, in consideration of CEO, the MRF system gives the best

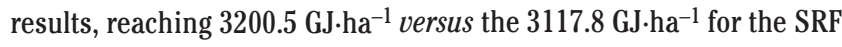
system.

Consequently, the NER (energy output compared to the energy consumption) for the biomass production is much more favorable for the MRF system (NER=42.1) than for the SRF (NER=36.4).
Table 3. Environmental and energy results related to the functional unit $(\mathrm{FU}=1$ ha of short rotation forestry and medium rotation forestry).

\begin{tabular}{|c|c|c|c|}
\hline Results & Unit of measure & SRF & MRF \\
\hline CEO & GJ eq.ha ${ }^{-1}$ & $3117.8(100 \%)$ & $3200.5(102.7 \%)$ \\
\hline CED & GJ eq.hat ${ }^{-1}$ & $83.3(100 \%)$ & $74.2(89.0 \%)$ \\
\hline $\mathrm{NER}=\mathrm{CEO} / \mathrm{CED}$ & - & $36.4(100 \%)$ & $42.1(115.7 \%)$ \\
\hline $\begin{array}{l}\text { Fixed } \mathrm{CO}_{2} \\
\text { (in the total biomass) }\end{array}$ & $\mathrm{t} \mathrm{CO}_{2} \mathrm{eq} \cdot \mathrm{ha}^{-1}$ & $370.8(100 \%)$ & $380.6(102.7 \%)$ \\
\hline GHG emissions & $\mathrm{kg} \mathrm{CO}$ eq.ha ${ }^{-1}$ & $5660.5(100 \%)$ & $5307.4(93.8 \%)$ \\
\hline GWP & $\mathrm{t} \mathrm{CO}_{2} \mathrm{eq} \cdot \mathrm{ha}^{-1}$ & $-365.1(100 \%)$ & $-375.3(102.8 \%)$ \\
\hline
\end{tabular}

SRF, short rotation forestry; $\mathrm{MRF}$, medium rotation forestry; CEO, cumulative energy output; $\mathrm{CED}$, cumulative energy demand; NER, net energy ratio; $\mathrm{GHG}$, green house gases; GWP, global warming potential.

Table 4. Short rotation forestry and medium rotation forestry cultivations system: greenhouse gases emissions for each operation.

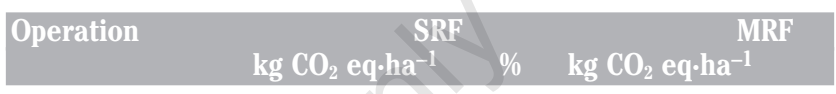

\begin{tabular}{lcccc} 
Organic fertilization & 154.5 & $2.7 \%$ & 137.1 & $2.6 \%$ \\
Ploughing & 98.9 & $1.7 \%$ & 87.8 & $1.7 \%$ \\
\hline Planting* & 245.4 & $4.3 \%$ & 108.2 & $2.0 \%$ \\
Harrowing & 116.4 & $2.1 \%$ & 103.3 & $1.9 \%$ \\
\hline Chemical weed control & 94.4 & $1.7 \%$ & 91.8 & $1.7 \%$ \\
Pest control* $^{*}$ & 72.9 & $1.3 \%$ & 51.2 & $1.0 \%$ \\
\hline Mechanical weed control $^{*}$ & 755.2 & $13.3 \%$ & 1005.3 & $18.9 \%$ \\
Nitrogen fertilization* $^{*}$ & 1094.7 & $19.3 \%$ & 588.0 & $11.1 \%$ \\
\hline Harvesting & 1402.0 & $24.7 \%$ & 905.6 & $17.1 \%$ \\
Biomass transport & 558.1 & $9.8 \%$ & 1276.1 & $24.0 \%$ \\
\hline Soil restoration & 125.9 & $2.2 \%$ & 111.7 & $2.1 \%$ \\
On-field emissions $^{\circ}$ & 948.1 & $16.7 \%$ & 841.3 & $15.9 \%$ \\
\hline Total & 5660.5 & $100 \%$ & 5307.4 & $100 \%$ \\
\hline
\end{tabular}

SRF, short rotation forestry; MRF, medium rotation forestry. *Including the mechanical operation and the employed material (cuttings/rod, chemical, fertilizer); ${ }^{\circ}$ Emissions from the soil due to mineral and organic nitrogen application.

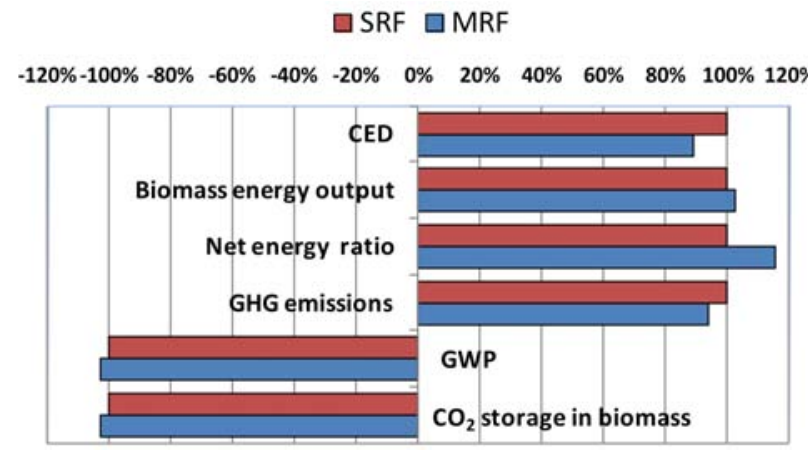

Figure 2. Poplar short rotation forestry (SRF) and medium rotation forestry (MRF) energetic and environmental compared performances. The SRF cultivation system is assumed as baseline (index $=100 \%$ ). CED, cumulative enregy demand; GHG, greenhouse gases; GWP, global warming potential. 


\section{Discussion}

In Italy, the most important specie planted for energy use (wood chip production) is the poplar (Bergante et al., 2010; Bacenetti and Fiala, 2011). The biomass yield and its quality (i.e., cellulose, lignin and ash contents) depend heavily on several factors which must be taken into account. In this paper, the cultivation techniques (field operations, fertilizers, chemicals and water etc.) as well as the cultivation system (cutting frequency) have been carefully considered.

Poplar plantations managed under the MRF cultivation system provide better environmental performances than those under the SRF system. This result can be extended to other short rotation coppice species also cultivated in Italy. González-García et al. (2012) checked the cultivation of black locust under the same two management systems and also their results confirm that the MRF system gives a higher biomass yield with a less intensive production process in terms of CED (lower number of operations). Higher biomass yields for MRF poplar plantations have also been identified by Fang et al. (1999) and by Guidi et al. (2009).

Taking into account the results obtained in this paper, special attention should be paid to some aspects in order to further reduce the environmental impact related to the SRF and the MRF cultivation systems. In particular, these aspects concern the use of $\mathrm{N}$-fertilisers and the intensity of certain agricultural operations (mechanical weed control, biomass harvesting and transport) which represent the hot spots both for GHG emissions and for energy consumption.

NER is considerably higher for the MRF (+15.7\%) than for the SRF system. However, under both systems, NER is higher than values obtained in previous research (14-19 in Turhollow and Perlack, 1991; 29 in Matthews, 2001; 8.8 in Walle et al., 2007; 8.0 in Manzone et al., 2009). In any case, it must be considered that, in the present study, the wood chip yield is quite a lot higher.

Nitrogen mineral fertilisation has been identified as a very intensive operation and the most energy-demanding step of the entire biomass production cycle (Gasol et al., 2009; Di Candilo et al., 2010; Fiala and Bacenetti, 2012a and 2012b). The use of manure (or digestate from anaerobic digestion plants) instead of mineral fertilisers could help to reduce the energetic and the environmental loads.

Overall, under the studied conditions, a comparison of the SRF and the MRF systems shows that the poplar plantation with a longer rotation achieves the best result in terms of both energy resources and the environment. This difference is certainly due to the higher MRF system yield but also to: i) the lower nitrogen fertilisation; ii) the different planting material; and iii) the low intensity of applied mechanisation.

The above results do not refer to small and experimental plots but concern two real farm poplar plantations with a total surface of 4.5 ha. For most of the field operations, the data inventory was drawn up on the results of specific field tests carried out during the first growing years.

Further research will take collect experimental data also regarding future operations and, in addition, will compare several poplar plantations characterised by the same management system.

\section{Conclusions}

Two SRC poplar plantations (managed under two different cultivation systems), located in the Lombardy region of northern Italy, devoted to biomass production for energy purposes (wood chips), were monitored in detail. The best cultivation system to obtain environmentally more sustainable wood chips was clearly identified. Several differences were observed in terms of fertiliser requirements and intensive agricultural activities. According to the environmental results, the MRF, based on a 5 -year cutting frequency, is the best cultivation system to obtain a more environmentally sustainable biofuel source, characterised by higher biomass yield, lower energy requirements and lower levels of $\mathrm{CO}_{2}$ emissions.

Under both the SRF and the MRF cultivation systems, the environmental and energy hot spots were identified as: i) mineral fertilisation; ii) mechanical weed-control; iii) harvesting and biomass transport

\section{References}

Althaus H.J., Chudacoff M., Hischier R., Jungbluth N., Osses M., Primas A. 2007. Life cycle inventories of chemicals. Ecoinvent report No. 8, v2.0 EMPA 2007. Swiss Centre for Life Cycle Inventories, Dübendorf, Switzerland.

Althaus H, Bauer C, Doka G, Dones R, Hischier R, Hellweg S, Humbert S, Köllner T, Loerincik Y, Margni M, Nemecek T. 2009. Implementation of life cycle impact assessment methods. Ecoinvent report No. 3, v2.1. Swiss Centre for Life Cycle Inventories, Dübendorf, Switzerland.

Bacenetti J., Fiala M. 2011. Short Rotation Coppice in Italy: a model to asses economic, energetic and environmental performances of different crop systems. World Renewable Energy Congress 2011. Linköping, Sweden.

Bergante S., Facciotto G., Minotta G. 2010. Identification of the main site factors and management intensity affecting the establishment of Short-Rotation-Coppices (MRF) in Northern Italy through Stepwise regression analysis. Cent. Eur. J. Biol. 4:522-30.

Di Candilo M., Ceotto E., Librenti I., Faeti V. 2010. Manure fertilization on dedicated Energy crops: productivity, Energy and carbon cycle implications. Proc. 14th Ramiran Int. Conf. FAO ESCORENA Network on "the Recycling of Agricultural, Municipal and Industrial Residues in Agriculture", Lisbon, Portugal, p 4.

Fang, S., Xu, X., Lu, S., Tang, L. 1999. Growth dynamics and biomass production in short-rotation poplar plantations: 6-year results for three clones at four spacings. Biomass Bioenerg. 17:415-25.

Fiala M., Bacenetti J. 2012a. Economic, energetic and environmental impact in Short Rotation Coppice harvesting operations. Biomass Bioenerg. 42:107-13.

Fiala M., Bacenetti J. 2012b. Model for economic, energy and environmental evaluation in biomass productions. J. Agricult. Engineer. 43:e5.

Fiala M., Bacenetti J., Scaravonati A., Bergonzi A. 2010. Short rotation coppice in Northern Italy: comprehensive sustainability. 18th Eur.Biomass Conf. Exhibit. Lyon, France, 342-8.

Gasol C.M., Brun F., Mosso A., Rieradevall J., Gabarrell X. 2010. Economic assessment and comparison of acacia energy crop with annual traditional crops in Southern Europe. Energy Policy 38:5927.

Gasol C.M., Gabarrell X., Anton A., Rigola M., Carrasco J., Ciria P., Rieradevall J. 2009. LCA of poplar bioenergy system compared with Brassica carinata energy crop and natural gas in regional scenario. Biomass Bioenerg. 33:119-29.

González-García S., Bacenetti J., Murphy R.J., Fiala M. 2012. Present and future environmental impact of poplar cultivation in Po Valley (Italy) under different crop management systems. J. Clean. Prod. 26:56-66.

Guidi W., Piccioni E., Ginanni M., Bonari E. 2008. Bark content estimation in poplar (Populus deltoides L.) short-rotation coppice in Central Italy. Biomass Bioenerg. 32:518-24.

Guidi, W., Tozzini, C., Bonari, E. 2009. Estimation of chemical traits in poplar short rotation coppice at stand level. Biomass Bioenerg. 33:1703-9. 
Guinée J.B. (final editor), Gorrée M., Heijungs R., Huppes G., Kleijn R., de Koning A, Van Oers L, Wegener A, Suh S, Udo de Haes H. 2001. Life cycle assessment: An operational guide to the ISO standards. Final report, May 2001. Centre of Environmental Science, Leiden University, Leiden, The Netherlands.

Heller M.C., Keoleian G.A., Mann M.K., Volk T.A. 2004. Life cycle energy and environmental benefits of generating electricity from willow biomass. Renew. Energ. 29:1023-42.

IS0. 2006. Environmental management - Life cycle assessment Principles and framework. Norm ISO 14040:2006. International Organization for Standardization Publ., Geneva, Switzerland. Available from: http://www.iso.org/iso/catalogue_detail?csnumber $=37456$

Manzone M., Airoldi G., Balsari P. 2009. Energetic and economic evaluation of a poplar cultivation for the biomass production in Italy.
Biomass Bioenerg. 33:1258-64.

Matthews R.W. 2001. Modelling of energy and carbon budgets of wood fuel coppice systems. Biomass Bioenerg. 21:1-19.

Spinelli R., Nati C., Magagnotti N. 2008. Harvesting Short-Rotation Poplar plantations for biomass production. Croat. J. For. Eng. 29:129-39.

Turhollow F., Perlack D. 1991. Emissions of $\mathrm{CO}_{2}$, from energy crop production. Biomass Bioenerg. 1:129-35.

VDI-Richtlinien. 1997. Cumulative energy demand terms, definitions, methods of calculation. VDI-Richtlinie 4600, Düsseldorf, Germany.

Walle I.V., van Camp N., van de Casteele L., Verheyen K., Lemeur R. 2007. Short-rotation forestry of birch, maple, poplar and willow in Flanders (Belgium) I - Biomass production after 4 years of tree growth. Biomass Bioenerg. 31:267-75. 